\title{
molecules
}

ISSN 1420-3049

(C) 2000 by MDPI

http://www.mdpi.org

\section{Synthesis and Antifungal Activity of Musa Phytoalexins and Structural Analogs}

\author{
Winston Quiñones, Gustavo Escobar, Fernando Echeverri*, Fernando Torres, Yoni Rosero, \\ Victor Arango, Gloria Cardona and Adriana Gallego \\ Department of Chemistry, Universidad de Antioquia, P. O. Box 1226, Medellin, Colombia \\ Tel.: (57+4)2105658, Fax: (57+4)2330120, E-mail: echeveri@catios.udea.edu.co
}

Received: 18 January 2000; revised form 14 July 2000/Accepted: 14 July 2000 /Published: 26 July 2000

\begin{abstract}
Several perinaphthenone/phenylphenalenone compounds were synthesized to establish a relationship between structure and antifungal activity against Mycosphaerella fijiensis. Substitutions on the unsaturated carbonyl system or addition of a phenyl group reduced antibiotic activity.
\end{abstract}

Keywords: phenylphenalenones, synthesis, antifungal activity, Mycosphaerella fijiensis.

\section{Introduction}

Phytoalexins are natural antibiotic compounds proposed as fungicides or templates for production of new pesticides [1]. Recently, the search for novel antifungal compounds has received special attention as a result of an enhanced microbial resistance to current pesticides.

Banana plants are affected by the pathogenic fungi Fusarium oxysporum var. cubensis type 4 and Mycosphaerella fijiensis, causal agents of the diseases named Black Sigatoka and Panama Disease, respectively. These diseases can drastically reduce banana production by as much as ca. 20\% [2]. Under colonization by these microorganisms or treatment of the leaves with kanamycin, banana plants produce two types of phytoalexins, 9-phenylphenalenones (also known as musanolones [3]) and 4phenylphenalenones [4], The main aim of the present work was to synthesize several structurally-related compounds and to determine the relationship between phytoalexin structure and their antifungal effects against $M$. fijiensis.

\section{Results and Discussion}

The planned synthetic approach involved a 1,4-addition of a Grignard reagent to a perinaphthenone, followed by reduction with $\mathrm{DDQ}$, epoxidation with ${ }^{\mathrm{t}} \mathrm{BuOOH}$ and finally enolization induced by acid treatment (Figure 1). 


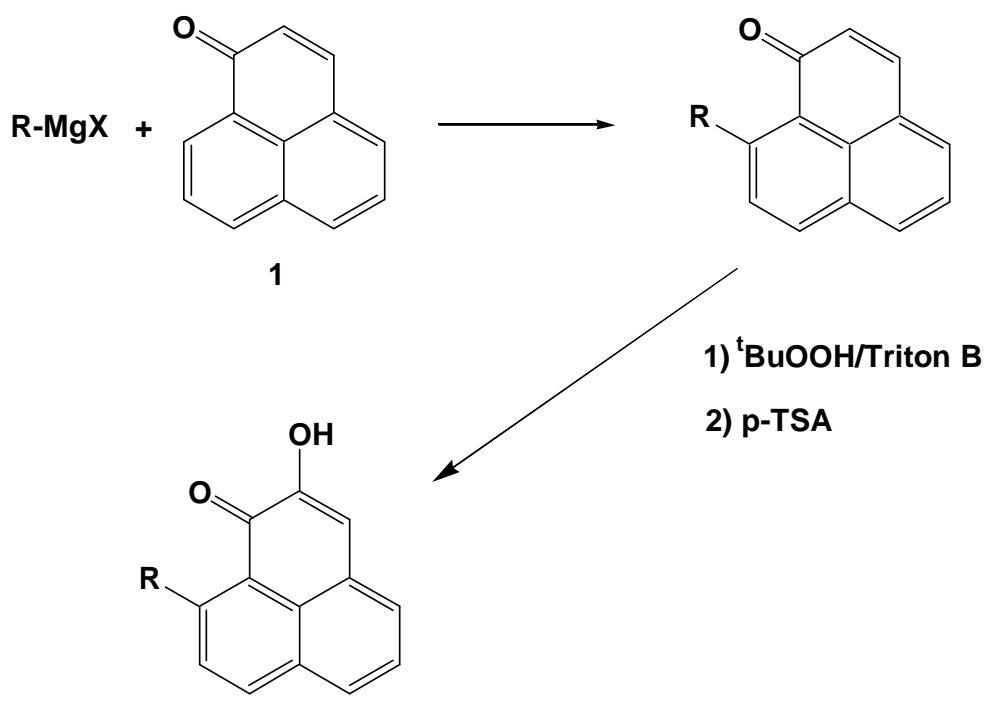

Figure 1. Synthesis of phenylphenalenones.

Previously, we have used this reaction to unambiguously confirm the structure of $4^{\prime}$-methoxyirenolone, a natural phytoalexin [5]; in addition, aryl Grignard reagents have also been used for the synthesis of extended phenalenones [6]. Other compounds such as irenolone [4-(4'hydroxy)phenylphenalenone)], and 4-phenylphenalenone were obtained from natural sources, as described elsewhere [1,5]. The results of the synthesis are summarized in Table 1; products derived from addition to the 2-en-1-one system were obtained in less than $5 \%$ yield.

Table 1. Structure and yield of phytoalexins and structural analogues.

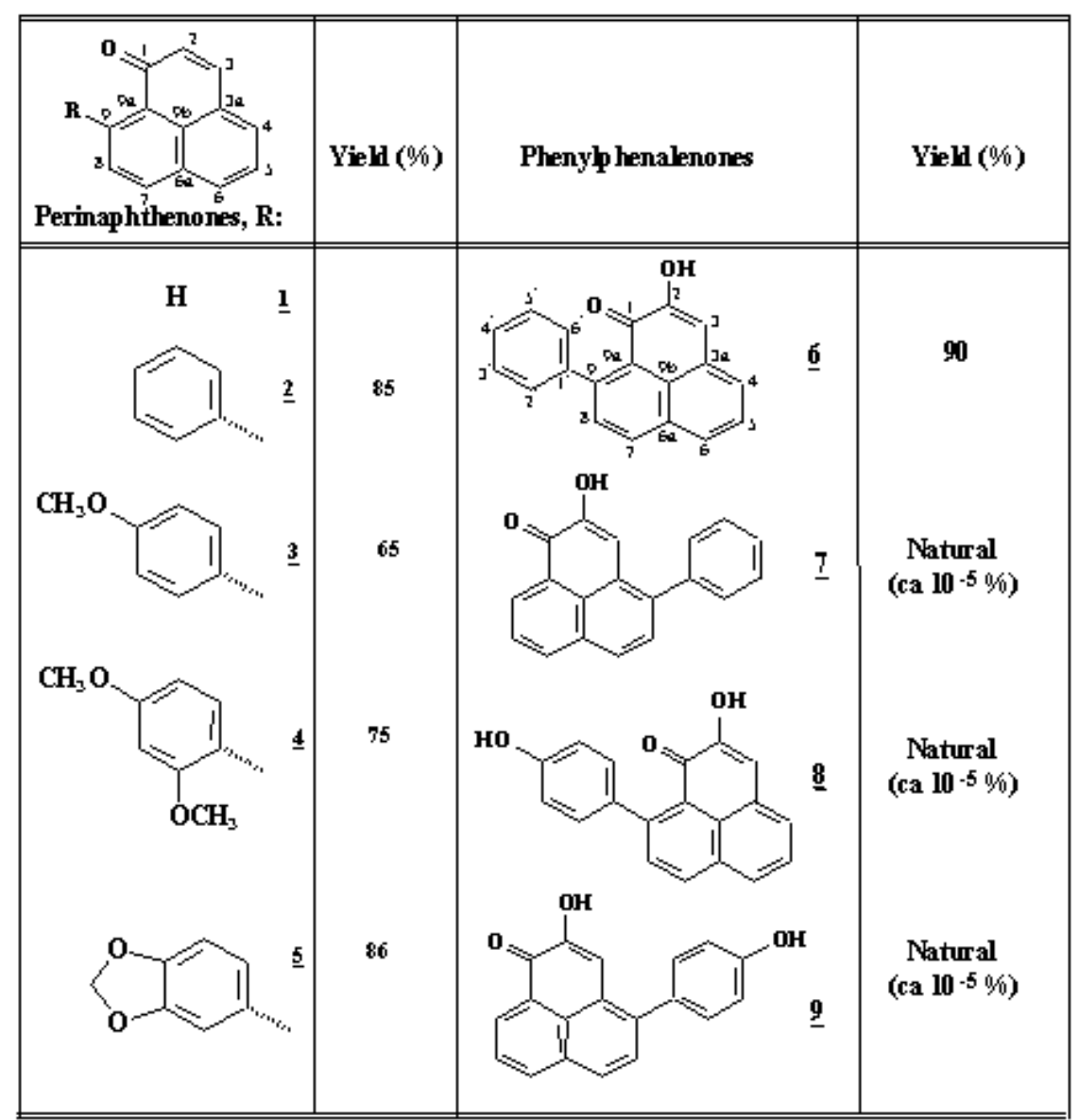


Activity was measured by the effect of the compounds on the weight of an established Mycosphaerella fijiensis colony (Figure 2). In this figure the results for each compound are represented by six bars (doses at 10.0, 50.0 and $100.0 \mathrm{ppm}$ and measurements at 7, 12 and 15 days). When the antibiotic activity detected was very low (e.g. compound 3), the corresponding bars are not displayed. Compound 7 was only tested at 50 and $100 \mathrm{ppm}$ due to limited availability.

Perinaphthenone (1H-phenalen-1-one, 1) was the most active antifungal compound assayed. Complete mycelial growth inhibition was observed at 50-100 ppm and its action remained over 15 days. This action was similar to benomyl, while 9-phenylperinaphthenone (2) showed slightly reduced activity. Additional substitution on the side phenyl group (compounds 3, 4 and 5) drastically reduces antibiotic properties. Natural phytoalexins (compounds 6-9) were less effective when compared to the results obtained above, although 9-phenylphenalenone 6 exhibited significant activity during the first days of experimentation.

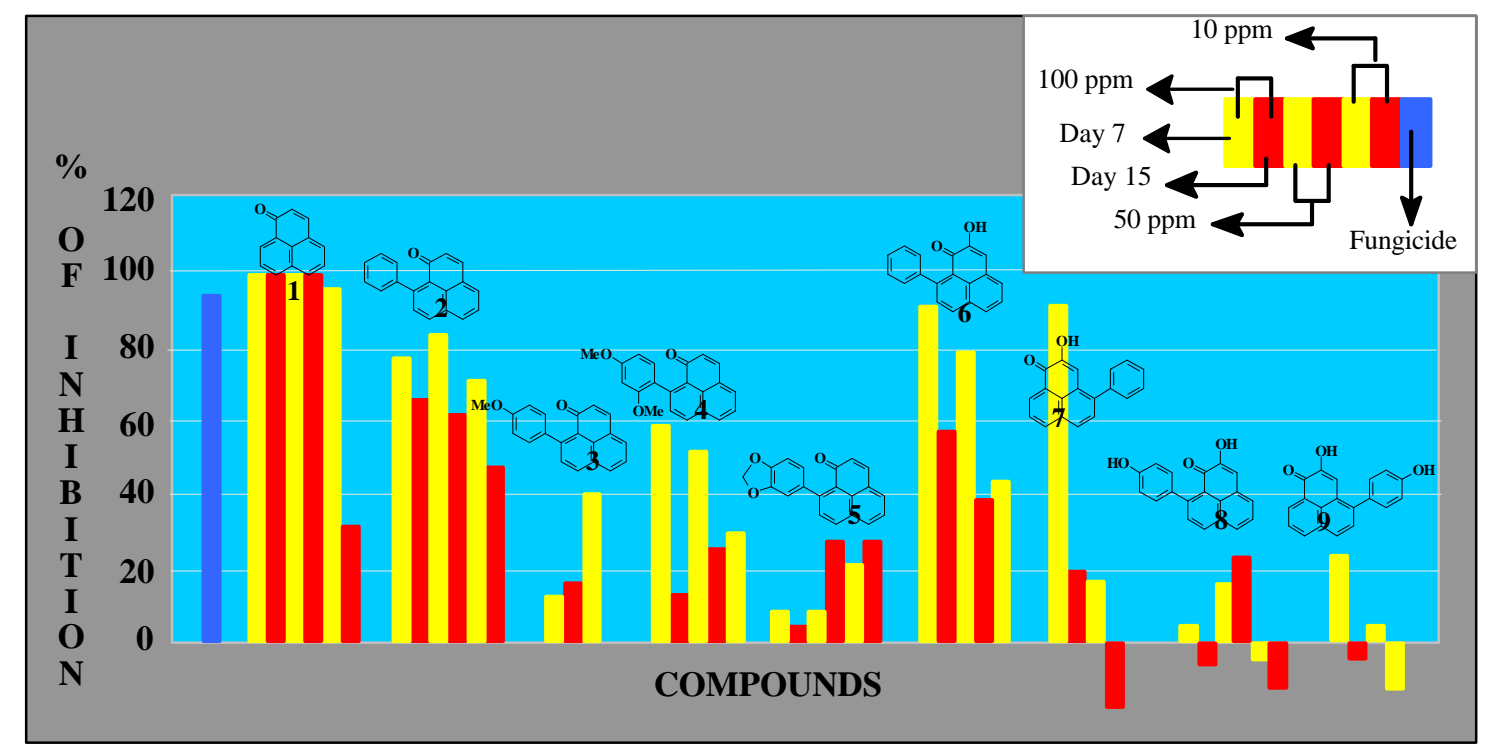

Figure 2. Antifungal activity on M. fijiensis growth (mycelial weight).

Concerning the effects on spore germination, perinaphthenone (1) at 50-100 ppm, was a more active antibiotic than the commercial fungicides tested (benomyl, propioconazole, tridermorph), as shown in Figure 3. The other compounds, including the phytoalexins, displayed only moderate effects.

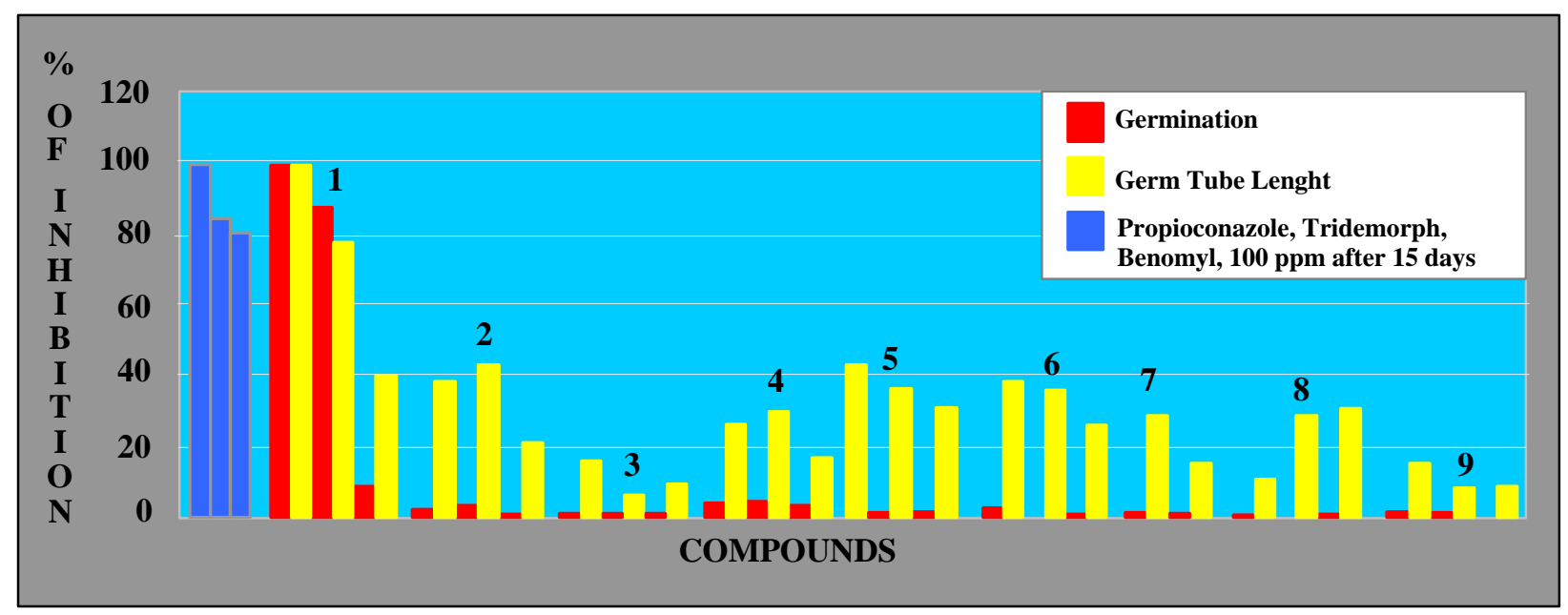

Figure 3. Antifungal activity on M. fijiensis spores. 
These results indicate the important antifungal properties of synthetic substances $\mathbf{1}$ and $\mathbf{2}$. Although perinaphthenone (1) is an efficient singlet oxygen sensitizer [7], very limited information is available about its mode of action. Formation of singlet oxygen and damage to biomolecules (DNA, proteins, fatty acids etc) could be an explanation (Figure 4).

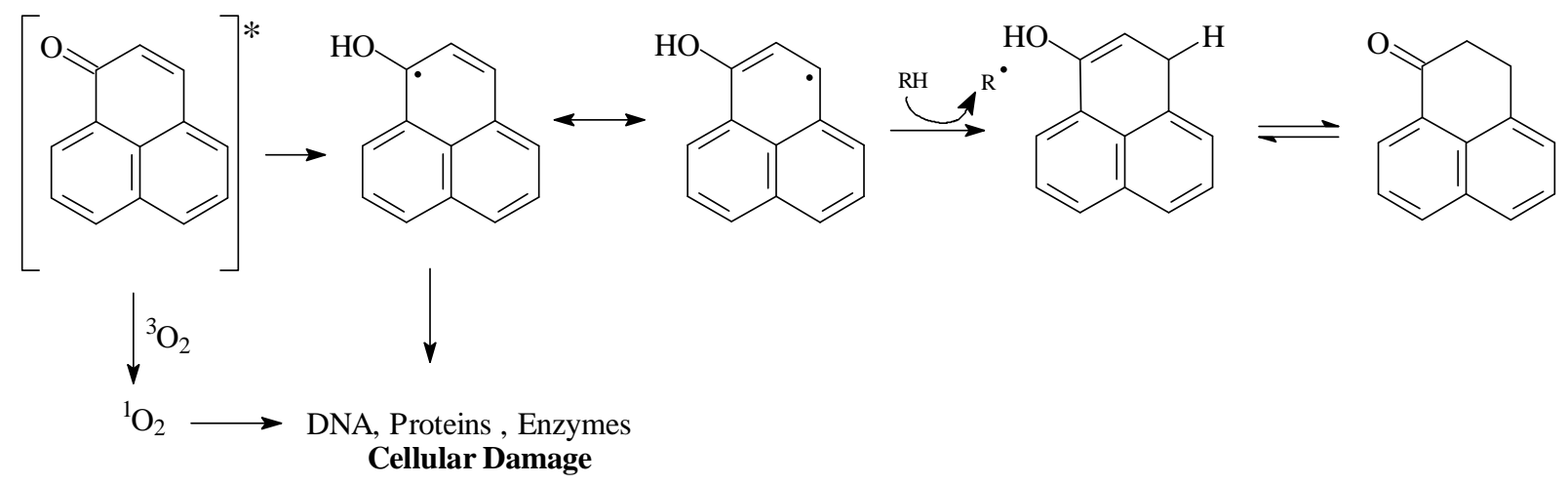

Figure 4. Singlet oxygen and biological effects by perinaphthenone.

However, more complex biochemical interactions could be involved, since the growth inhibition profile observed is very diferent from the spore germination one: e.g. 9-phenyl-perinaphthenone (2) is powerful as an inhibitor whereas in germination it is practically inactive. Although it has been reported that a hydroxyphenyl group in the phenylphenalenone moiety is essential for antibiotic activity against Colletotrichum musa [9], this action seems to be dependent on other factors, especially molecular shape and the inductive effect of substituents.

Perinaphthenone, with its planar tricyclic system, may act as a DNA intercalating agent. On the other hand, steric influence effects are displayed in the reduced activity of phenylperinaphthenone 2 (Figures 2 and 3). Some derivatives (compounds 3-5) do not exhibit significant antifungal activity, probably due to modifications in their insertion ability or a lack of stabilization of potential free radicals on the side ring due to inductive effects of the substituents. Other natural products such as hypericin and perylenequinone displayed an activity related to presence of free radicals [8] and oxygen activation. Finally, the natural phytoalexins assayed (compounds 6-9) displayed low antifungal activity, probably due to poor solubilization and incorporation to the agar media. Further investigations concerning the in vivo effects of this kind of phenalenones are ongoing, since they represent a new type of antifungal compounds which display long lasting antibiotic activity.

\section{Experimental}

\section{General}

$400 \mathrm{MHz}{ }^{1} \mathrm{H}$ and $100 \mathrm{MHz}{ }^{13} \mathrm{C} \mathrm{NMR}$ spectra were recorded for $\mathrm{CDCl}_{3}$. solutions on in a Bruker 400 Avance instrument. MS were registered on a VG Micromass ZAB-2F at $70 \mathrm{eV}$; IR on a Perkin Elmer 1600 (FTIR) instrument. Perinaphthenone (1) was obtained from a commercial source (Aldrich). All anhydrous reactions were carried out under an argon atmosphere using freshly dried solvents. 
General synthetic procedures

A solution of $1(0.47 \mathrm{~g}, 0.003 \mathrm{~mol})$ in THF $(5 \mathrm{~mL})$ was added to the appropriate Grignard reagent (0.004 mol; prepared from the respective bromide and $\mathrm{Mg}$ in THF (10 ml)). After stirring for $20 \mathrm{~min}$ at $-70^{\circ} \mathrm{C}$ the reaction mixture was allowed to reach room temperature and then was quenched with an aqueous saturated solution of $\mathrm{NH}_{4} \mathrm{Cl}$. The aqueous phase was extracted with dichloromethane and the combined organic extracts were washed with brine, dried over $\mathrm{Na}_{2} \mathrm{SO}_{4}$ and evaporated to dryness. The crude material dissolved in $\mathrm{CH}_{2} \mathrm{Cl}_{2}$ was treated with DDQ (1.0 eq), refluxed for $3 \mathrm{~h}$ and then allowed to reach room temperature. After water addition the $\mathrm{CH}_{2} \mathrm{Cl}_{2}$ phase was separated and purified by HPLC (hexane-EtOAc 99:1)

The preparation of the 2-hydroxyphenylphenalenone type compounds was carried out as follows: a solution of the compound ( $3 \mathrm{mmol}$, obtained as above) in benzene $(15 \mathrm{~mL})$ was cooled at $0^{\circ} \mathrm{C}$ and treated with Triton $\mathrm{B}(3 \mathrm{mmol}$, benzene) and t-butylhydroperoxide $(3 \mathrm{mmol})$ for $3 \mathrm{~h}$. The reaction was quenched with $\mathrm{NH}_{4} \mathrm{Cl}$, the organic phase was separated, dried and evaporated. The residue (2.5 mmol) was dissolved in diethyl ether and several crystals of p-toluenesulfonic acid were added. After workup the final product was purified by HPLC, affording deep-yellow solids.

Satisfactory spectroscopic data were obtained for all compounds.

Spectral data

\section{Perinaphthenone (1)}

${ }^{1} \mathrm{H}$ NMR: $\delta 8.57(\mathrm{dd}, \mathrm{J}=1.1$ and $7.4 \mathrm{~Hz}, 1 \mathrm{H}, \mathrm{H}-9), 8.13(\mathrm{dd}, \mathrm{J}=0.8$ and $8.0 \mathrm{~Hz}, 1 \mathrm{H}, \mathrm{H}-7), 7.95(\mathrm{~d}$, $\mathrm{J}=8.5 \mathrm{~Hz}, 1 \mathrm{H}, \mathrm{H}-6), 7.72(\mathrm{~d}, \mathrm{~J}=7.6 \mathrm{~Hz}, 1 \mathrm{H}, \mathrm{H}-8), 7.72(\mathrm{~d}, \mathrm{~J}=7.6 \mathrm{~Hz}, 1 \mathrm{H}, \mathrm{H}-4), 7.68$ (d, J= 9.8 Hz, 1H, $\mathrm{H}-3), 7.53(\mathrm{dd}, \mathrm{J}=7.6$ and $8.2 \mathrm{~Hz}, 1 \mathrm{H}, \mathrm{H}-5), 6.68(\mathrm{~d}, \mathrm{~J}=9.8 \mathrm{~Hz}, 1 \mathrm{H}, \mathrm{H}-3) ;{ }^{13} \mathrm{C}$ NMR: $\delta 185.16(\mathrm{C}-1)$, 141.38 (C-3), 134.51 (C-3a), 131.67 (C-9a), 131.55 (C-9), 131.08 (C-4), 129.80 (C-6a), 128.96 (C-7), 128.73 (C-6), 127.29 (C-5), 126.99 (C-8), 126.60 (C-9a), 126.23 (C-2)

\section{9-Phenylperinaphthenone (2)}

${ }^{1} \mathrm{H}$ NMR: $\delta 8.18(\mathrm{~d}, \mathrm{~J}=8.3 \mathrm{~Hz}, 1 \mathrm{H}, \mathrm{H}-7), 8.05(\mathrm{~d}, \mathrm{~J}=8.2 \mathrm{~Hz}, 1 \mathrm{H}, \mathrm{H}-6), 7.79$ (d, J= 7.0 Hz, 1H, H4), $7.70(\mathrm{~d}, \mathrm{~J}=9.7 \mathrm{~Hz}, 1 \mathrm{H}, \mathrm{H}-3), 7.62(\mathrm{dd}, \mathrm{J}=7.1$ and $8.2 \mathrm{~Hz}, 1 \mathrm{H}, \mathrm{H}-5), 7.61(\mathrm{~d}, \mathrm{~J}=8.3 \mathrm{~Hz}, 1 \mathrm{H}, \mathrm{H}-8)$, 7.45-7.34 (m, 5H, H-2',3',4',5',6'), 6.62 (d, J= 9.7 Hz, 1H, H-2); ${ }^{13} \mathrm{C}$ NMR: $\delta 186.13$ (C-1), 148.07 (C9), 143.32 (C-1'), 140.75 (C-3), 134.09 (C-7), 132.18 (C-9a), 132.11 (C-6), 132.01 (C-8), 131.76 (C4), 130.94 (C-2), 128.94 (C-3a), 128.81 (C-9b), 128.67 (C-3',5'), 128.27 (C-6'), 127.55 (C-2',4'), $126.76(\mathrm{C}-6 \mathrm{a}), 126.48(\mathrm{C}-5)$.

\section{9-(p-Methoxyphenyl)perinaphthenone (3)}

${ }^{1} \mathrm{H}$ NMR: $\delta 8.15$ (d, J= $\left.8.3 \mathrm{~Hz}, 1 \mathrm{H}, \mathrm{H}-7\right), 8.03$ (d, J= 8.2 Hz, 1H, H-6), 7.76 (d, J=6.4 Hz, 1H, H4), $7.68(\mathrm{~d}, \mathrm{~J}=9.7 \mathrm{~Hz}, 1 \mathrm{H}, \mathrm{H}-3), 7.62(\mathrm{dd}, \mathrm{J}=7.0 \mathrm{~Hz}$ and $7.9 \mathrm{~Hz}, 1 \mathrm{H}, \mathrm{H}-5), 7.61$ (d, J= 8.3 Hz, 1H, H8), $7.34\left(\mathrm{dd}, \mathrm{J}=2.1\right.$ and $\left.6.6 \mathrm{~Hz}, 2 \mathrm{H}, \mathrm{H}-3^{\prime}, 5^{\prime}\right), 7.03\left(\mathrm{dd}, \mathrm{J}=2.1\right.$ and $\left.6.6 \mathrm{~Hz}, 2 \mathrm{H}, \mathrm{H}-2^{\prime}, 6^{\prime}\right), 6.62(\mathrm{~d}, \mathrm{~J}=9.7$ $\mathrm{Hz}, 1 \mathrm{H}, \mathrm{H}-2), 3.90$ (s, 3H, -OCH 3 ); ${ }^{13} \mathrm{C}$ NMR: $\delta 186.26$ (C-1), 159.51 (C-4'), 147.96 (C-9), $140.64(\mathrm{C}-$ 3), 135.36 (C-1'), 134.08 (C-7), 132.38 (C-6), 132.11 (C-8), 132.01 (C-9a), 131.72 (C-4), 131.07 (C- 
2), $129.86\left(\mathrm{C}^{2} 2^{\prime}, 6^{\prime}\right), 128.95$ (C-3a), 128.86 (C-9b), 126.59 (C-5), 126.41 (C-6a), 114.23 (C-3',5'), $55.66\left(-\mathrm{OCH}_{3}\right)$

\section{9-(2',4'-Dimethoxyphenyl)-perinaphthenone (4)}

${ }^{1} \mathrm{H}$ NMR: $\delta 8.19$ (d, J= 8.4 Hz, H-7), 8.05 (d, J= 8.0 Hz, H-6), 7.78 (d, J=6.8 Hz, H-4), 7.70 (d, J= $9.6 \mathrm{~Hz}, \mathrm{H}-3$ ), 7.62 (dd, J=7.2 and $8.4 \mathrm{~Hz}, \mathrm{H}-5$ ), 7.60 (d, J=8.4 Hz, H-8), 7.16 (d, J= 8.0 Hz, H-6'), $6.66\left(\mathrm{dd}, \mathrm{J}=2.4\right.$ and $9.7 \mathrm{~Hz}, \mathrm{H}-5^{\prime}$ ), 6.62 (d, J= 9.6 Hz ,H-2), 6.58 (d, J= 2.4 Hz, H-3'), 3.92 (s, $\left.\mathrm{OCH}_{3}\right), 3.73\left(\mathrm{~s},-\mathrm{OCH}_{3}\right) ;{ }^{13} \mathrm{C} \mathrm{NMR}: \delta 185.66 \mathrm{C}-1,160.49 \mathrm{C}-2$ ', $157.52 \mathrm{C}-4$ ', $143.46 \mathrm{C}-9,140.07 \mathrm{C}-3$, 133.67 C-7, 132.12 C-6', 131.68 C-6, 131.57 C-8, 130.98 C-9a, 130.28 C-4, 129.28 C-2, 128.39 C-3a, 128.22 C-9b, 126.96 C-5, 126.02 C-1', 104.57 C-5', 98.77 C-3', 55.57- $\mathrm{OCH}_{3}, 55.35-\mathrm{OCH}_{3}$.

\section{9-(3',4'-Methylenedioxy)perinaphtenone (5)}

${ }^{1} \mathrm{H}$ NMR: $\delta 8.15(\mathrm{~d}, \mathrm{~J}=8.3 \mathrm{~Hz}, 1 \mathrm{H}, \mathrm{H}-7), 8.03(\mathrm{~d}, \mathrm{~J}=8.1 \mathrm{~Hz}, 1 \mathrm{H}, \mathrm{H}-6), 7.78(\mathrm{~d}, \mathrm{~J}=6.8 \mathrm{~Hz}, 1 \mathrm{H}, \mathrm{H}-$ 4), $7.69(\mathrm{~d}, \mathrm{~J}=9.7 \mathrm{~Hz}, 1 \mathrm{H}, \mathrm{H}-3), 7.63(\mathrm{dd}, \mathrm{J}=7.2 \mathrm{~Hz}$ and $8.1 \mathrm{~Hz}, 1 \mathrm{H}, \mathrm{H}-5), 7.60$ (d, J= 8.3 Hz, 1H, H8), 6.93 (d, J= 7.8 Hz, 1H, H-6'), 6.88 (s, 1H, H-2'), 6.86 (d, J= 7.8 Hz, 1H, H-5'), 6.62 (d, J= 9.7 Hz, 1H, H-2), 6.04 (s, 2H, -O-CH $\left.{ }_{2}-\mathrm{O}-\right) ;{ }^{13} \mathrm{C}$ NMR : $\delta 186.12$ (C-1), 148.02 (C-4'), 147.67 (C-3'), 147.45 (C-9), 140.68 (C-3), 137.03 (C-1'), 134.09 (C-7), 132.25 (C-6'), 132.15 (C-6), 132.11 (C-8), 131.97 (C-9a), 130.97 (C-4), 130.22 (C-2), 128.87 (C-3a), 126.87 (C-9b), 126.58 (C-5), 126.11 (C-6a), $109.46\left(\mathrm{C}-5\right.$ '), $108.82(\mathrm{C}-2 '), 101.46\left(\mathrm{O}-\mathrm{CH}_{2}-\mathrm{O}-\right)$

Antifungal activity

Inhibition of mycelial growth [10]

Mycosphaerella fijiensis was initially isolated from naturally infected banana plantations located in Uraba (Colombia); cultures were routinely grown in PDA medium. Sterile distilled water suspensions of conidia were obtained by washing the surface of the sporulating colony growing in PDA at $26^{\circ} \mathrm{C}$; these conidia were dispersed in PDA medium in petri dishes and incubated at $26^{\circ} \mathrm{C}$ for 4 days. Some of these colonies were placed in petri dishes with PDA medium containing different concentrations of the compounds to be assayed or with $\mathrm{EtOH}$ only. After incubation in the dark at $26^{\circ} \mathrm{C}$, radial mycelial growth was measured after 7, 9, 12 and 15 days of incubation. The inhibition of fungal growth was estimated as a percentage of the control values. In addition, colonies were recovered, agar traces were eliminated and the mycelia were weighed.

\section{Inhibition of spore germination}

Ascospores discharged from infected banana leaves were used [11]; germination and length of the germ tubes were established microscopically in 50-150 ascospores. Appropriate controls of fungal cultures without compounds and controls with or without $1 \% \mathrm{EtOH}$ were run. The following reference compounds were used to determine the threshold of detection: propiconazole, tridemorph and benomyl. Experiments were done in quadruplicate, and data were analyzed by one-way analysis of variance (ANOVA) 
Acknowledgements: The authors thank Colciencias (Colombia) and the Universidad de Antioquia for financial support; G.E. is indebted to Colciencias for a fellowship.

\section{References and Notes}

1. Keen, N. "Evaluation of Role of Phytoalexins". In Plant Disease Control; Stapless, R., Toenniessen, G., Eds.; John Wiley: New York, 1981; p 339.

2. Simmonds, N. W. Bananas. $2^{\text {nd }}$ ed.; Longman: London, 1982; p 512.

3. Luis, J.G.; Quiñones, A.; Echeverri, F.; Kishi, P.; Garcia, F. Musanolones: four 9-phenylphenalenones from rhizomes of $M$. acuminata. Phytochemistry 1996, 41, 753-757.

4. Luis, J.G.; Echeverri, F.; Quiñones, W.; Brito, I.; Lopez, M.; Torres, F.; Cardona, G.; Aguiar, Z.; Rojas, M. Irenolone and emenolone: two new types of phytoalexin from Musa paradisiaca. J. Org. Chemistry 1993, 58, 4306-4308.

5. Luis, J.G.; Quiñones, W.; Echeverri, F.; Grillo, T.; Perales, A.; Gonzalez, J.A. Intermediates with biosynthetic implications in de novo production of phenylphenalenone-type phytoalexins by Musa acuminata. Revised structure of emenolone. Tetrahedron 1995, 51, 4117-30.

6. Katritzky, A.R.; Li, J.; Xie, L. [3+3] benzannulations of benzenoid- and heteroaromatic-ring systems. Tetrahedron 1999, 55, 8263-8293.

7. Oliveros, E.; Bossmann, S.; Nonell, S.; Marti, C.; Heit, G.; Tröscher, G.; Neuner, A.; Martínez, C.; Braun; A. Further characterization of perinaphthenone (1H-phenalen-1-one) as $\mathrm{O}_{2}\left({ }^{1} \Delta_{\mathrm{g}}\right)$ standard: photochemical decomposition in 1,4-dioxane and DMA: http://www.photobiology.com/iupac98/nonel/pn_oliv.htm

8. Park, J.; English, D. S.; Wannamuelher, Y.; Carpenter, S.; Petrich, J. W. The role of oxygen in the antiviral activity of hypericin and hypocrellin. Photochemistry \& Photobiology 1998, 68, 593-597

9. Kamo T.; Kato N.; Hirai N.; Tsuda M.; Fujioka D.; Ohigashi H.. Phenylphenalenone-type phytoalexins from unripe bungulan banana fruit. Bios. Biotech. \& Biochemistry 1998, 62, 95-101.

10. Bailey, J.; Carter, A.; Skipp, A. The use and interpretation of bioassay for fungitoxicity of phytoalexins in agar media. Physiol. Plant Pathol. 1976, 8, 189-194.

11. Molina, G.; Krausz, J. A phytotoxic activity in extracts of broth cultures of Mycosphaerella fijiensis var. difformis and its use to evaluate host resistance to Black Sigatoka. Plant Disease 1989, 73, 142-143.

Sample Availability: Available from MDPI.

(C) 2000 by MDPI (http://www.mdpi.org). 